\title{
Auto-eficácia empreendedora de estudantes de ensino médio das escolas estadutais de Limeira
}

Rose Mary Almeida Lopes ${ }^{1}$

Edmundo Inácio Júnior ${ }^{2}$

\footnotetext{
${ }^{1}$ ANEGEPE

${ }^{2}$ Faculdade de Ciências Aplicadas / UNICAMP ( Universidade Estadual de Campinas )
} 


\section{AUTO-EFICÁCIA EMPREENDEDORA DE ESTUDANTES DE ENSINO MÉDIO DAS ESCOLAS ESTADUAIS DE LIMEIRA}

Resumo: Este estudo discute o potencial empreendedor de jovens sob o enfoque da Psicologia Social, com os conceitos de atitudes que afetam as intenções e o comportamento. O modelo conceitual revisto por Athayde e Hart (2012) utiliza atitudes que são impactadas pela educação empreendedora e que afetam a auto-eficácia empreendedora em jovens. Este trabalho contribui, particularmente por ter traduzido e adaptado, para uso no Brasil, o instrumento desenvolvido por estes autores - Attitudes to Enterprise Test (ATE), que foi aplicado em 1971 a estudantes de ensino médio de escolas estaduais da cidade de Limeira, SP, não expostos à educação empreendedora. Examinaram-se as influências de variáveis demográficas e socioeconômicas como: gênero, grupo racial, faixas de renda familiar, séries dos alunos, experiência empreendedora e intenção de empreender, sobre a auto-eficácia empreendedora e as atitudes que a compõem: criatividade, realização, controle, intuição e liderança. Um dos resultados mais interessantes é o da influência da experiência empreendedora e da intenção de empreender.

Palavras chave: Potencial empreendedor. Auto-eficácia empreendedora. Atitudes. Ensino médio.

\section{Introdução}

Em todo o mundo, os jovens ( 15 a 24 anos) são a parte da população economicamente ativa que é mais suscetível e passível de desemprego. No Brasil, fechamos o ano de 2017 com um total de 70,9 milhões de pessoas com até 24 anos estão sem trabalho.

O relatório Global Employment Trends for Youth 2017 (ILO, 2017), mostra que a razão era de 3 jovens para cada adulto desempregado, razão que se tem mantido nos últimos 10 anos. Mesmo em países desenvolvidos os jovens experimentaram o desemprego; entre os países da União Europeia, no primeiro quadrimestre de 2017, 29\% dos jovens dos 28 países da EU-28 estavam desempregados, e 33\% deles na zona do Euro. Se contabilizados entre os países da $\mathrm{OECD}$, eram 2,8 milhões de jovens à margem do mercado de trabalho.

$\mathrm{Na}$ América Latina e Caribe este cenário é ainda menos promissor, dado que se esperava um índice de 19,6\% no fechamento de 2017, com perspectiva de se manter neste nível em 2018, e grande parte devido ao fraco desempenho econômico brasileiro. Para o Brasil, se estimava fechar 2017 com 30\% dos jovens desempregados, uma taxa histórica, não alcançada desde 1991 (ILO, 2017, p. 17), mais que o dobro da média mundial - 13,1\%. Situação equivalente à de países árabes - Síria em guerra com taxa de 30,6\%. Apenas 36 dos 190 países estudados pela ILO (OIT sigla em Português) mostraram uma situação pior do que a do nosso país.

Sabe-se e demonstra-se que a educação é um fator que auxilia a abreviar e facilitar a entrada dos jovens no mercado de trabalho. O mesmo relatório da ILO (2017) mostra que o período de transição entre finalizar o ensino de II grau e se posicionar no mercado de trabalho

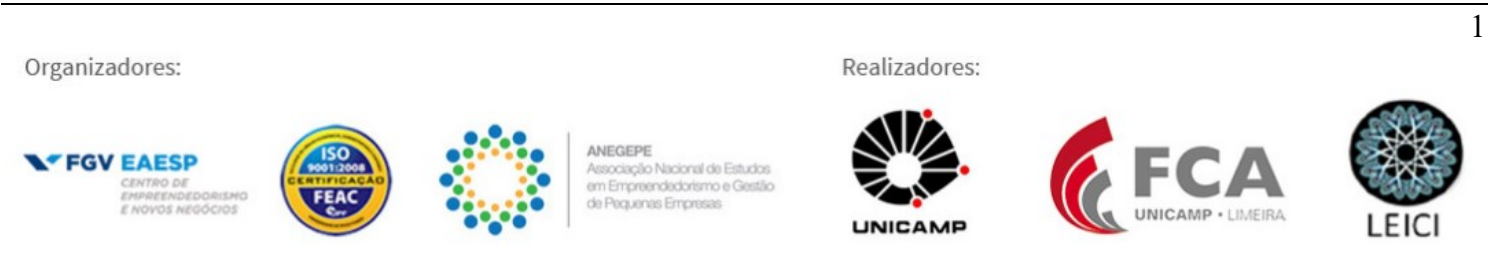


tem uma média de 14,3 meses, comparativamente aos 22,2 meses para os que concluem o primeiro grau, e 8,5 meses para os que se graduam em faculdades.

Este período poderá ser maior ou menor em função do país (com alta, média ou baixa renda média), do nível e qualidade da educação e de gênero (ILO, 2017). E, também do grupo racial: a Pesquisa Nacional por Amostra de Domicílios Contínua (PNAD Contínua), do IBGE, no terceiro trimestre de 2017, mostrou que as pessoas de pele preta e parda têm mais desvantagens: seis em cada dez pessoas desempregadas tinham a pele preta ou parda.

$\mathrm{O}$ desalinhamento entre as habilidades do jovem e as exigidas atualmente pelo mercado por ser um fator impeditivo de que ascenda a empregos. Assim, a falta de foco em apresentar as carreiras bem como preparar os estudantes para o mundo do trabalho implica que os jovens de menor poder aquisitivo, e mesmo os de classe média, não seriam estimulados e encorajados a elevarem seu nível de aspiração/expectativa para melhorarem sua mobilidade social.

E, cada vez mais a empregabilidade depende das chamadas competências empreendedoras. Então, o Empreendedorismo é percebido pelos governos e diferentes agentes sociais como uma solução política para os problemas do desemprego juvenil. Deste modo, o ensino de Empreendedorismo de modo a estimular atitudes e habilidades típicas dos empreendedores nos jovens não só poderá ajudá-los a desenvolver habilidades percebidas como críticas para a empregabilidade como pode estimular a decisão de seguir na direção de possuir um negócio ou gerar o próprio emprego (auto-emprego).

Para que uma sociedade se desenvolva economicamente, é importante que tenha um estoque de potenciais empreendedores, para que o ambiente econômico seja resiliente e se autorrenove (SHAPERO, 1981, 1982). Se o ambiente oferecer apoio social, cultural, informação, conhecimento tácito e recursos tangíveis, estes potenciais aflorariam, e estas pessoas se mostrariam mais inclinadas a tomar a iniciativa e aproveitar as oportunidades.

Então, parece ser interessante e importante que se possa detectar, o quanto antes, os jovens com potencial empreendedor; e mais importante ainda se, depois de identificados, pudessem ser estimulados, orientados para que fizessem melhor uso deste potencial.

Os autores Athayde e Hart (2012) desenvolveram um modelo conceitual de potencial empreendedor em jovens no âmbito educacional, e criaram um instrumento de avaliação deste potencial Attitudes to Enterprise Test (ATE), que mede a auto-eficácia empreendedora. Este teste pode ser utilizado em estudos de resultados das ofertas de cursos e de programas de EE. $\mathrm{O}$ instrumento foi validado na Inglaterra; e apontou-se então a necessidade de verificar sua utilidade em outros países.

Então, o objetivo deste estudo é examinar os resultados obtidos em amostra de estudantes de ensino médio de escolas públicas de Limeira, não expostos à educação empreendedora, do potencial empreendedor - auto-eficácia empreendedora - com este instrumento traduzido para o Português; e verificar a influência de variáveis demográficas e socioeconômicas sobre as atitudes que compõem este potencial empreendedor ou autoeficácia empreendedora.

Deste modo espera-se contribuir para a discussão sobre o potencial empreendedor, quais variáveis que o influenciam, e oferecer um instrumento adaptado especialmente para o contexto de jovens do ensino médio. Este serve não somente para identificar a auto-eficácia empreendedora, mas, sobretudo, serve para que todos os envolvidos com o oferecimento de

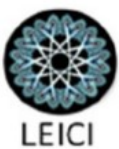


educação empreendedora possam monitorar os impactos das ofertas no potencial empreendedor dos alunos.

Este trabalho compreende: esta introdução, a importância do empreendedorismo entre jovens no Brasil, o modelo conceitual do potencial empreendedor, a metodologia e procedimentos, a análise e discussão dos resultados, e as considerações finais.

\section{Importância do empreendedorismo entre jovens no Brasil}

No Monitoramento Global de Empreendedorismo - GEM -, do qual o Brasil tem participado desde o ano 2000, os dados do relatório de 2016 apontam que China - com 26,4\% - e Brasil - com 28,1\% - despontam com mais alto percentual de empreendedores em potencial. Potencial medido pela intenção das pessoas de 18 a 64 anos de empreender no prazo de 3 anos. A faixa de idade de 18 a 24 anos despontou com $24 \%$ de desejo de empreender, quase $27 \%$ deles com ensino médio completo e superior incompleto.

Enfatiza-se que esta intenção de empreender parece ser mais impactada por fatores culturais do que a estabilidade política e a fase econômica dos países. Pois, no nosso caso, o país atravessou alta instabilidade econômica além do declínio econômico. Outros países com estabilidade em ambos os fatores não demonstraram tal potencial de empreender (casos da Alemanha, Rússia etc.).

No GEM adota-se um quadro referencial do processo empreendedor em que a fase primeira é a do potencial empreendedor. Na Figura 1 mostrada a seguir, verifica-se que o potencial é estimulado quando a pessoa percebe oportunidades no ambiente, quando ela avalia que tem conhecimentos e habilidades para explorá-la, não tem medo do fracasso, e manifesta atitudes positivas com respeito à possibilidade de explorar a oportunidade.

O GEM adota um agrupamento dos países segundo as bases que impulsionam suas economias. Assim, o Brasil se situa no grupo de economias impulsionadas por eficiência ou fatores. Ainda que o empreendedorismo no país esteja sendo impulsionado pela maior visibilidade e popularidade, por maior escolaridade e facilidade de abrir negócios mais simples e de menor escala de faturamento (MEI), as taxas de atividade também são influenciadas pelos ciclos econômicos (GEM, 2016, p. 29). Assim, nos últimos anos, dada a crise econômica pela qual se atravessa, com mercado de trabalho em retração, baixa renda média per capita, as poucas oportunidades tem motivado as pessoas para o empreendedorismo, ampliando-se o empreendedorismo por necessidade (GEM 2016, p. 25).

No Brasil, os percentuais de empreendedores iniciantes são importantes em todas as faixas de idade, sendo bastante significativos os $20,1 \%$ de 18 a 24 anos, seguidos de $22,9 \%$ na faixa etária dos 25 aos 34, e 19,7\% de 35 a 44 anos e declinando a partir daí (GEM, 2016, p. 36).

Os empreendedores de atividades em estágio inicial, no Brasil, com escolaridade com secundário completo representavam 20,5\% (GEM 2016, p. 38). Isto indica que seria muito importante que se apresentassem oportunidades de educação para o empreendedorismo para este nível de escolaridade. Este apresentou percentual maior de envolvimento com TEA do que o nível com alguma educação $(19,5 \%)$ e pós-secundário $(14,4 \%)$.

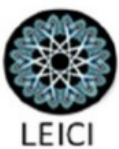




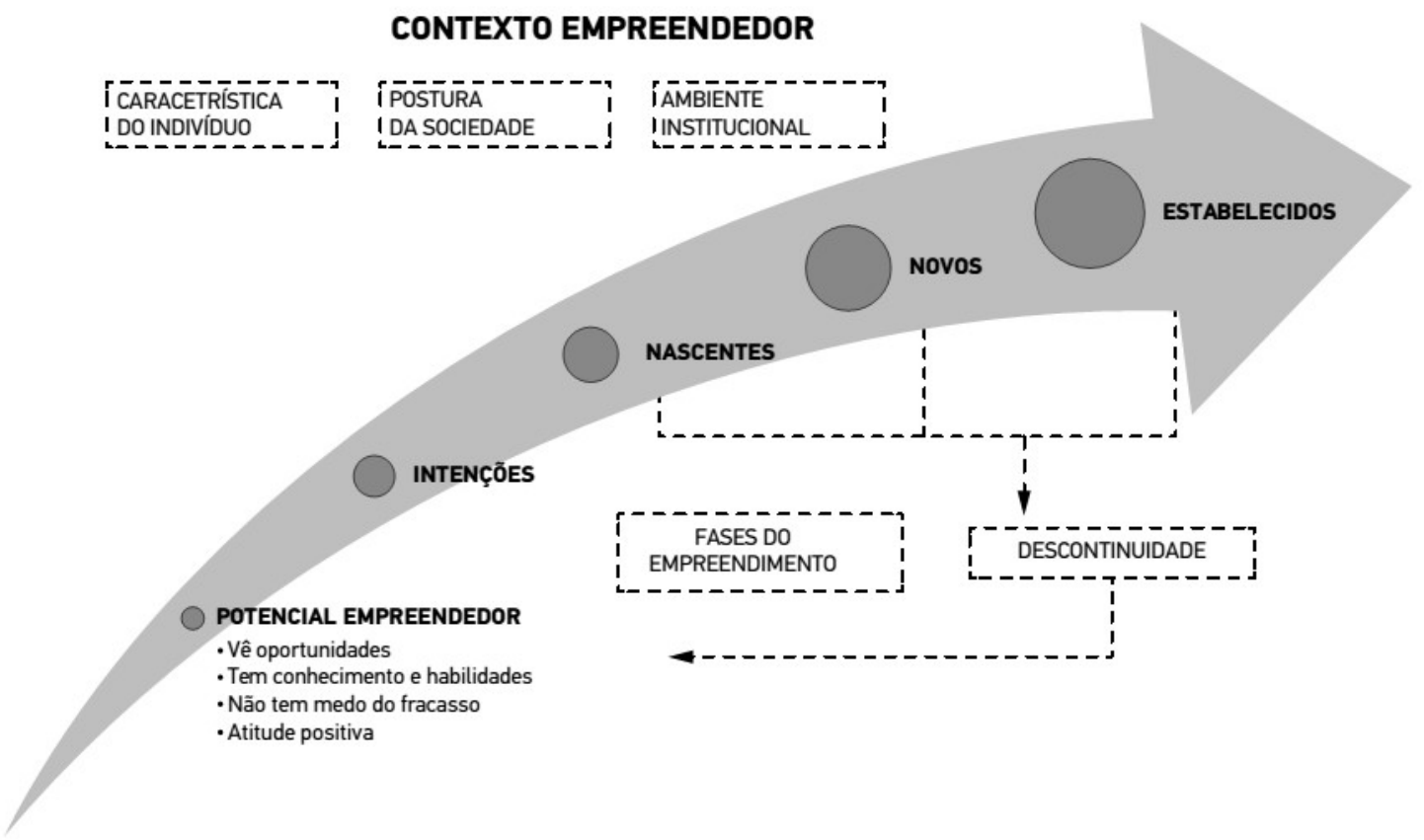

Figura 1 - Modelo de Processo Empreendedor adotado pelo GEM.

Fonte: Recuperado de GEM 2016, p. 18

Com respeito a gênero, em termos de TEA, a participação de homens e mulheres tem sido bem equilibrada nos últimos anos. Em 2016 foi de 19,2\% entre os homens e de 19,9\% entre as mulheres (GEM 2016, p. 35). Esta diferença se acentua entre os negócios estabelecidos há mais de 42 meses: a diferença cresce para 5,3\%: homens com $19,6 \%$ e mulheres com 14,3\%.

Quanto à relação entre TEA e faixa de renda, o GEM adota apenas 3 faixas de renda, distribuindo a população igualmente nos 3 estratos, classificando em menor, central e maior. Ante esta classificação, é interessante enfatizar que o país apresenta taxas de TEA bem equilibradas nas diferentes faixas. Menor faixa de renda com 19,4\%, central com 21,6\% e maior com $18 \%$. Ou seja, o que vai diferenciar depois nas taxas de empreendimentos estabelecidos são outros fatores, entre os quais a maior ou menor capacidade de financiamento por meio de familiares. (GEM, 2016, 41).

$\mathrm{Na}$ pesquisa GEM, especialistas atuantes no ecossistema empreendedor são chamados a avaliar fatores favoráveis e limitantes ao empreendedorismo no país. No que se refere à abertura e manutenção de novos negócios, 31,2\% dos especialistas entrevistados indicaram o baixo nível de educação e capacitação para empreender (GEM, 2016, p.89). Cabe destacar ainda que os especialistas do Brasil quanto de outros países indicaram que a educação empreendedora é deficiente nos níveis de ensino fundamental e médio, o que aponta a falta de prioridade dada pelos governos ao ensino de empreendedorismo nestes níveis, assim como de outros agentes da sociedade (GEM, 2016, p. 94).

Deste modo, percebe-se que mesmo que os jovens possam ter potencial para empreender, este potencial poderá ser melhor desenvolvido por meio de ações educacionais,

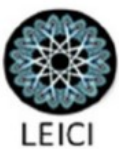


quer nas escolas públicas quanto nas privadas. É importante mencionar aqui que a educação empreendedora, tal como definida pela Comunidade Europeia, pode ser entendida com um foco duplo: visa o desenvolvimento das competências empreendedoras, envolvendo conhecimentos, habilidades e atitudes que propiciam implementar as ideias por meio da ação. Por outro lado, compreende a ação criativa e inovadora que pode acontecer em todos os contextos da vida das pessoas: dentro de organizações, no desenvolvimento de novos projetos, negócios e iniciativas (Lopes, Lima e Nassif, 2017).

\section{Modelo conceitual de potencial empreendedor}

$\mathrm{Na}$ Psicologia Social o conceito de potencial empreendedor refere-se a algo latente, causal e temporalmente anterior à intenção. Então, o problema é como identificar, motivar e encorajar estes potenciais empreendedores.

Durante algumas décadas as medidas de potencial empreendedor se assentavam, sobretudo, em traços de personalidade e características demográficas. Ajzen (1991) criticou a abordagem baseada em personalidade, pois os traços são vistos como estáticos, e tanto as teorias de personalidade quanto os traços seriam representações simplificadas que não levariam em conta as cognições e as influências de fatores situacionais específicos sobre as ações. E, segundo Robinson et al. (1991) e McCline et al. (2000) estes estudos não teriam sido capazes de demonstrar validade discriminante ou convergente.

$\mathrm{Na}$ literatura, sobretudo nas duas últimas décadas, tem se destacado a visão do empreendedorismo como processo, no qual os processos mentais seriam mais importantes do que os traços de personalidade. Então, empreendedorismo é conceituado como um comportamento planejado e intencional (Bird, 1988, Katz \& Gartner, 1988). E, destaca-se o papel central da intencionalidade e os processos mentais, estudados por meio das teorias das cognições sociais (Katz \& Shepherd 2003, Haynie \& Shepherd, 2009, Thompson 2009).

Já se tinha revelado como as atitudes influenciavam as intenções e estas impactavam os comportamentos. Deste modo, tanto as atitudes quanto as ações seriam antecedentes do comportamento empreendedor (Krueger \& Carsud, 1993). Depois, Azjen, em sua teoria e estudos, enfatizou o papel das intenções e como estas servem como preditoras do comportamento futuro, e mostrou como as intenções são afetadas pelas atitudes.

Empreendedores de sucesso demonstram um conjunto de comportamentos que se assentam em habilidades e atributos como: autonomia (controle pessoal), orientação para realização, criatividade, liderança e lidar com ambiguidade e incerteza. Deste modo o potencial empreendedor é concebido como um constructo multidimensional.

Athayde \& Hart (2012) decidiram utilizar uma abordagem de atitudes similar ao que foi utilizado por Robinson et al. (1991). Selecionaram 5 dimensões que seriam expressões de resultados chave da educação empreendedora: criatividade, controle pessoal, orientação para realização ou para dinamismo, pensamento intuitivo e inspirar e motivar outros (habilidades de liderança e de trabalho em equipe).

Athayde (2009) desenvolveu o Teste de Atitudes Empreendedoras, instrumento para medir o potencial empreendedor em jovens, aplicando-o inicialmente em uma amostra de estudantes de ensino médio, da cidade de Londres (UK), de 14 a 17 anos, e desenvolveu os testes de validade com uma segunda amostra de 328 universitários. Encontraram algumas

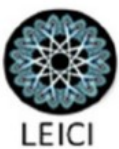


afirmativas ineficazes de cada constructo, reduziram o número de afirmativas e omitiram a escala de intuição completamente.

Houve necessidade de rever o modelo teórico, e o conceito de auto-eficácia foi incorporado no modelo de potencial empreendedor em jovens. Então, Athayde e Hart (2012) conceituaram potencial empreendedor como alta eficácia empreendedora, que foi operacionalizada como atitudes positivas com respeito a cinco dimensões: liderança, realização, controle pessoal, criatividade e intuição.

Auto-eficácia é conceito que se origina na teoria cognitiva social, e segundo Bandura (1986), relaciona-se com iniciar e persistir num comportamento sob alta incerteza, estabelecer metas elevadas, reduzindo rigidez ante o medo e desamparo aprendido. A auto-eficácia percebida é o preditor mais forte de escolha de carreira e de reconhecimento de oportunidades, que é central para intenção de empreender (Scherer, Adam, Carley \& Wiebe, 1989).

Pessoa com alta auto-eficácia espera desempenhar bem um tarefa, dá-se melhor do que as que esperam se dar mal (Bandura \& Schunck 1981, Bandura 1986, 1997).

Acontece que auto-eficácia não é um traço global; relaciona-se com um domínio específico. Hmieleski \& Corbett (2007) enfatizaram a necessidade de identificar domínios específicos das dimensões. Assim, os instrumentos anteriores falharam ao não caracterizar o domínio específico das atitudes e ou habilidades.

O modelo conceitual de Athayde e Hart (2012) sobre o qual assentaram o desenvolvimento do teste de Atitude Empreendedora é mostrado na Figura 2. Com este modelo é que os autores desenvolveram a segunda versão do teste Attitudes to Enterprise Test, e realizaram todos os estudos de confiabilidade e validação. Deste modo, criaram um teste robusto e eficaz para a identificação do potencial empreendedor em jovens, bem como para o monitoramento das iniciativas de educação empreendedora. A única atitude cuja confiabilidade interna foi menor, foi a de intuição, mas com valor muito próximo - 0,659 - ao nível de aceitação - 0,7 Alpha de Cronbach. O estudo de validade de critério posterior com 328 alunos comprovou que foi capaz de discriminar entre alunos que possuíam dos que não possuíam ou estavam presentemente administrando um negócio. 


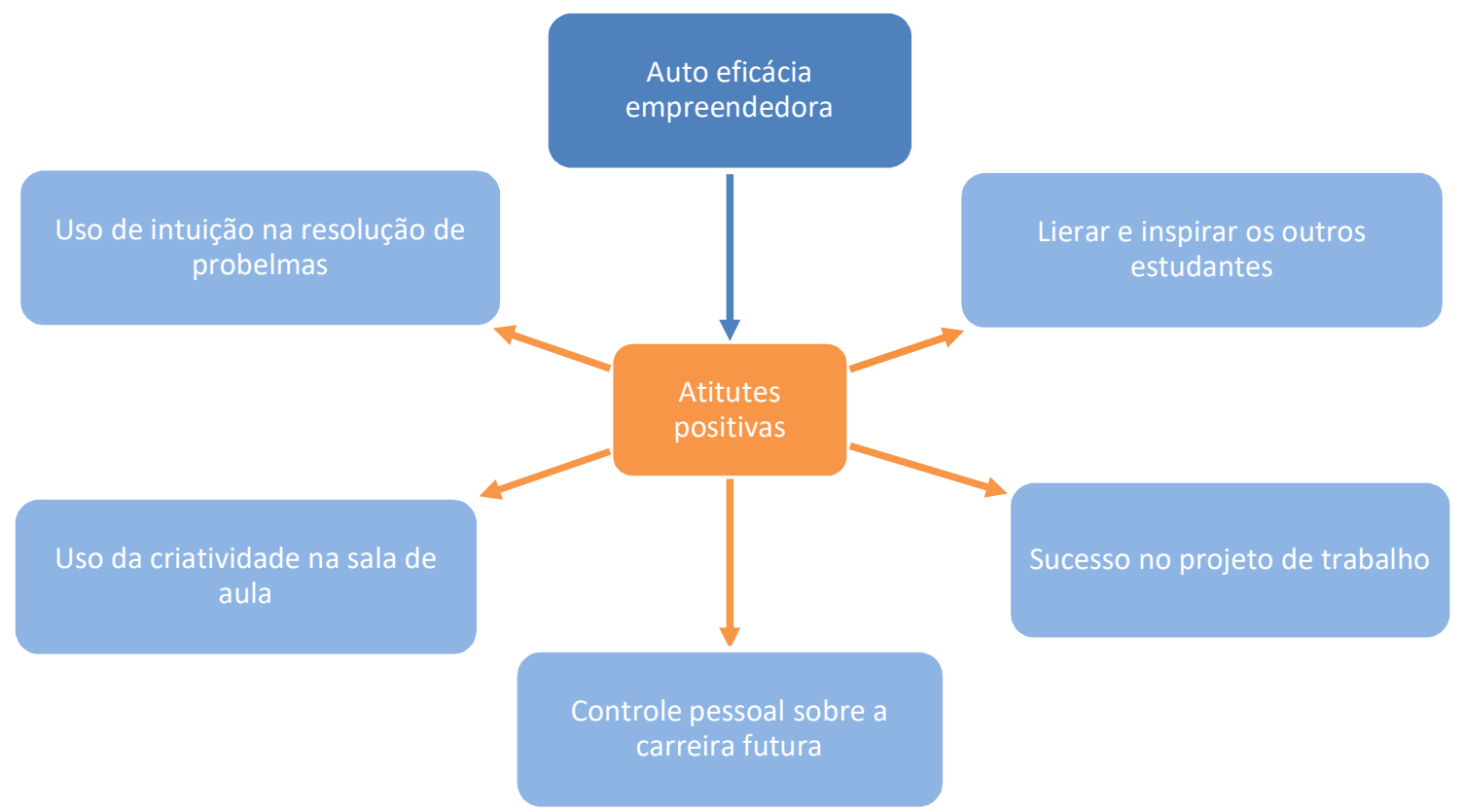

Figura 2: Modelo de potencial empreendedor - auto-eficácia empreendedora em jovens Fonte: Recuperado e adaptado de Athayde e Hart (2012).

Interessante notar que o modelo conceitual a que chegaram Athayde e Hart (2012) se relaciona bem com o resultado final de um robusto estudo de meta-análise desenvolvido por Rauch e Frese (2007, explicado em Lopes, 2013) em que, após varrerem as pesquisas feitas durante 200 anos, chegaram a oito (8) traços com relação significativa com a atividade empreendedora. Desses, quatro (4) deles estariam mais fortemente relacionados com o comportamento empreendedor, e são: motivação de realização, inovação, pró-atividade e autoeficácia, que se superpõem fortemente com o modelo proposto por Athayde e Hart, mas que enfocam as atitudes: realização, criatividade, controle pessoal (que se relaciona, ao menos parcialmente com pró-atividade, e a autoeficácia que seria a resultante final. Apenas a intuição não foi corroborada por Rauch \& Frese (2007).

As cinco atitudes que compõem o modelo de Athayde e Hart (2102) são conceituadas no Quadro 1:

\begin{tabular}{l|l}
\hline \multicolumn{1}{c|}{ Atitude } & \multicolumn{1}{c}{ Conceituação } \\
\hline Criatividade & $\begin{array}{l}\text { Inclui: flexibilidade, lidar com o inesperado, encontrar soluções para problemas } \\
\text { aparentemente insolúveis, encarando-os de maneira peculiar e inovadora, imaginando algo } \\
\text { extraordinário ( apud Athayde \& Hart, 2012, p.5, apoiando-se em outros autores). }\end{array}$ \\
\hline $\begin{array}{l}\text { Controle } \\
\text { Pessoal }\end{array}$ & $\begin{array}{l}\text { Crença que se refere a assumir o controle (locus de controle interno), associado à autoestima, } \\
\text { particularmente em jovens. É um pré-requisito para ação. (Athayde \& Hart, 2012, p.5, } \\
\text { baseados em vários autores). }\end{array}$ \\
\hline Realização & $\begin{array}{l}\text { Uma alta necessidade de realização foi identificada por McClelland como uma característica } \\
\text { dos empreendedores de sucesso. São pessoas que se mostram ativas, ocupadas, tomam } \\
\text { iniciativa, que acreditam no trabalho duro. (Athayde \& Hart, 2012, p.6, baseados em } \\
\text { diversos autores). }\end{array}$ \\
\hline
\end{tabular}




\begin{tabular}{l|l}
\hline Intuição & $\begin{array}{l}\text { Estaria relacionada à capacidade de lidar com incertezas e circunstâncias instáveis, ao } \\
\text { reconhecimento de oportunidade, mas também a uma maneira preferida da pessoa de reunir, } \\
\text { processar e avaliar informações (Athayde \& Hart, 2012, p.6, apoiados em vários autores). }\end{array}$ \\
\hline \multirow{L}{*}{ Liderança } & $\begin{array}{l}\text { Pressupõe dispor-se e gostar de assumir a responsabilidade por um grupo, e despertar a } \\
\text { expectativa de que faça isto. Facilidade para se relacionar bem com as pessoas, motivá-las a } \\
\text { fazer coisas, despertando entusiasmo nelas, e ser popular. Pessoas capazes de motivar os } \\
\text { outros para fazer as coisas e podem criar entusiasmo em outras pessoas" (Athayde \& Hart, } \\
\text { 2012, p.6, apoiando-se em outros autores). }\end{array}$ \\
\hline
\end{tabular}

Quadro 1 - Conceitos das Atitudes da Auto-Eficácia Empreendedora (Potencial Empreendedor) Fonte: Adaptado de Athayde e Hart (2012).

\section{Metodologia e procedimentos}

Usou-se a abordagem quantitativa, com pesquisa em campo em formato de survey. O estudo se caracteriza por ser exploratório, com objetivo de verificar os resultados obtidos, sobretudo pelo TAE, e sua capacidade de discriminação da influência de algumas variáveis. A pesquisa teve um planejamento ex-post-facto e foi transversal, realizado uma vez, sem continuidade (Cooper \& Schindler, 2003).

Para este estudo utilizou-se uma base de dados de uma pesquisa feita por alunos do Programa de Iniciação Científica Júnior (PICJr), em 2014 junto a estudantes, não expostos à educação empreendedora, das 3 séries de Ensino Médio, de 20 escolas estaduais de Limeira, cidade do interior do estado de São Paulo. A maioria das escolas da amostra se situava nas regiões Central e Sudoeste da cidade, e apenas uma escola era na região Nordeste.

O questionário continha questões formuladas pelos pesquisadores, e adaptadas de pesquisas nacionais e internacionais, fazendo-se testes de modo a promover a adequação de linguagem e a proximidade com os sujeitos da pesquisa. Foram, no mínimo, 4 versões do questionário até sua versão final. A cada versão os alunos do PICJr o respondiam para verificação da linguagem, identificação de alguma inconsistência, como perguntas duplicadas ou ambíguas ou mal formuladas, além de testar a diagramação de forma que o preenchimento fosse o mais simples possível e que houvesse encadeamento entre as seções e as perguntas dentro das seções.

O questionário fechado, com questões de múltipla escolha, com 32 itens, possuía 4 seções solicitando informações: demográficas e socioeconômicas, educação financeira, experiência empreendedora (exposição a/ou negócio próprio ou envolvimento com vendas) e intenção de empreender, e exposição a conceitos sobre sustentabilidade. Este estudo examinou a influência das variáveis demográficas e socioeconômicas, experiência empreendedora/ intenção de empreender, e o teste de auto-eficácia empreendedora. Este teste foi inserido no item 25 , composto pelas cinco dimensões das atitudes, sendo seis afirmativas para cada uma, totalizando 30 frases mostradas no Apêndice. Solicitava-se que o estudante pontuasse o grau de concordância com as afirmativas, numa escala Likert, de $1 \mathrm{a} 7$, com as seguintes graduações: Discordo Fortemente; Discordo; Discordo Parcialmente, Concordo Parcialmente; Concordo; e Concordo Fortemente.

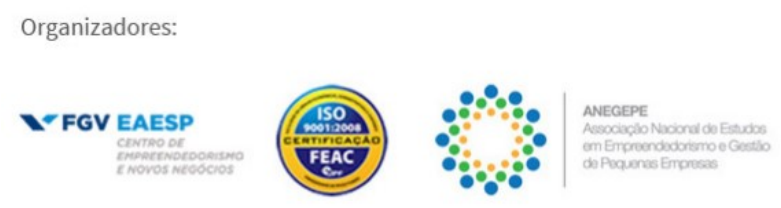

Realizadores:
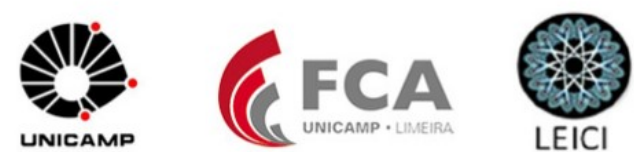
A aplicação dos questionários foi feita presencialmente: os estudantes das escolas foram orientados pelos alunos da UNICAMP, e depois foram sorteados aleatoriamente para responder ao questionário. O plano amostral considerou um nível de confiança de 5\%. Deste modo foram aplicados questionários respeitando as quantidades mínimas em cada escola. Assim, totalizaram 1971 questionários válidos.

Todas as análises baseiam-se nas comparações entre os valores obtidos pelas variáveis investigadas utilizando-se as variáveis demográficas e socioeconômicas. Os valores assumidos pelas dimensões do TAE são todas numéricas de forma que os valores representam a média aritmética simples, obtida para o total de alunos pesquisados em cada categoria de análise. Todas as análises estão respaldadas pela aplicação de teste de significância estatística (valor-F), para o qual é empregada a análise de variância (Anova). A análise de variância (Anova) foi aplicada para se acessar a significância estatística da diferença entre as médias. $\mathrm{O}$ valor-F obtido, traz a indicação da significância aos níveis de 5\%,1\% e 0,1\%. Todas as análises foram realizadas com o software SPSS v21.

\section{Análise e discussão dos resultados}

A Tabela 1 mostra as variáveis demográficas e socioeconômicas da amostra que são importantes para verificar algumas associações entre os resultados na auto-eficácia empreendedora e as atitudes que a compõem.

Os estudantes estão na faixa de 14 a 19 anos, concentrando-se na faixa de menos idade, em que $65 \%$ tem de 14 a 16 anos, e $35 \%$ tem de 17 a 19 anos.

Nota-se que a amostra é bem equilibrada com respeito ao gênero (Tabela 1), que a proporção maior se auto-refere como brancos, seguidos de $47 \%$ entre pardos e negros, com percentagem bem pequena de indígenas e de asiáticos. Relativamente à renda mensal, $62 \%$ da amostra se situa acima de $\mathrm{R} \$ 1500,00$ e praticamente um terço $(29,7 \%)$ com renda abaixo deste nível. Apenas $8 \%$ dos estudantes indicaram ter negócio próprio; entretanto, devemos lembrar que a média de idade destes alunos é de menos de 16 anos. No GEM 2016, a faixa de idade de 18 a 24 apresentou 20,1\% e os empreendedores com escolaridade secundária, 20,5\%, o que indica que chegando à idade legal, o envolvimento com empreendedorismo tende a crescer.

Tabela 1. Características Demográficas e Socioeconômicas.

\begin{tabular}{|c|c|c|c|c|c|c|c|}
\hline \multicolumn{2}{|c|}{ Gênero } & \multicolumn{2}{|c|}{ Grupo racial } & \multicolumn{2}{|c|}{ Renda Mensal Familiar } & \multicolumn{2}{|c|}{ Negócio Próprio } \\
\hline Categorias & $\%$ & Categorias & $\%$ & Categorias & $\%$ & Categorias & $\%$ \\
\hline Masculino & 46,9 & Asiático & 1,2 & Até $\mathrm{R} \$ 500,00$ & 3,3 & Sim & 8,1 \\
\hline Feminino & 48,9 & Branco & 50,7 & $\mathrm{R} \$ 500,01-\mathrm{R} \$ 1000,00$ & 10,0 & Não & 91,9 \\
\hline Sem resposta & 4,2 & Pardo & 34,2 & $\mathrm{R} \$ 1000,01-\mathrm{R} \$ 1500,00$ & 16,4 & & \\
\hline & & Negro & 11,6 & $\mathrm{R} \$ 1500,01-\mathrm{R} \$ 2500,00$ & 36,9 & & \\
\hline & & Indígena & 2,0 & $\mathrm{R} \$ 2500,01-\mathrm{R} \$ 4000,00$ & 22,9 & & \\
\hline & & Sem resposta & 0,3 & Acima de $\mathrm{R} \$ 4000,00$ & 8,3 & & \\
\hline & & & & Sem resposta & 2,2 & & \\
\hline
\end{tabular}

Fonte: Autoria própria com base em dados da pesquisa do PICJr. 
O Gráfico 1 demonstra as médias das respostas em relação às atitudes que compõem o auto-eficácia empreendedora, tal como aferida pelo Teste TAE. É possível identificar que as atitudes com maiores médias são controle pessoal, com 5,2 e realização, com 5,0. Entretanto, devemos lembrar que estas médias ainda estão longe de seu potencial máximo, que seria 7,0. Nas outras atitudes as médias continuam a declinar, como se pode observar nos resultados de intuição, liderança e criatividade. Aliás, chama a atenção que a menor média seja a de criatividade, atitude que é base em que se assentará a inovação, tão crítica para o desenvolvimento dos empreendedores. Com isso, pode-se dizer que que os jovens estudantes do ensino público da cidade de Limeira conseguem desenvolver um pouco mais as atitudes de controle pessoal e de realização. Mas, mesmo estas atitudes se beneficiariam muito se fossem desenvolvidas por meio de atividades e programas específicos de ensino de empreendedorismo.

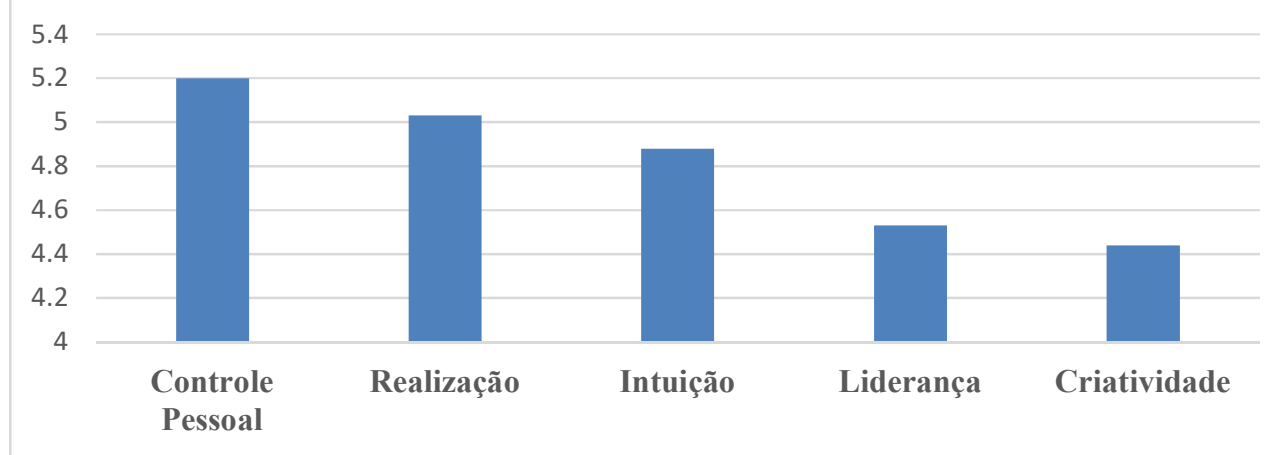

Gráfico 1. Médias nas atitudes

Fonte: Autoria própria com base em dados da pesquisa do PICJr.

As diferenças entre médias quanto ao gênero só mostraram significância $(\mathrm{p}<0,01)$ nas atitudes de realização e intuição, em favor das alunas, ou seja, elas mostram médias pouco maiores do que os alunos. Seria interessante investigar-se se esta diferença existiria antes mesmo de iniciarem os estudos do ensino médio ou se seria desenvolvida ao longo dele, e questionar se este desenvolvimento ligeiramente superior das alunas seria de fato atribuível ao contexto escolar.

Tabela 2. Comparação entre as médias da auto-eficácia empreendedora e das atitudes segundo gênero.

\begin{tabular}{l|c|c|c|c}
\hline \multirow{2}{*}{ Dimensão } & \multicolumn{3}{|c|}{ Gênero } & \multirow{2}{*}{$\begin{array}{c}\text { Teste de } \\
\text { Significância (F) }\end{array}$} \\
\cline { 2 - 4 } & Total & Masculino & Feminino & $3,113+$ \\
\hline Auto-Eficácia Empreendedora & 4,81 & 4,79 & 4,84 &, $044+$ \\
Criatividade & 4,44 & 4,46 & 4,42 &, $460+$ \\
Controle Pessoal & 5,21 & 5,22 & 5,20 & $\mathbf{8 , 0 6 1 * *}$ \\
Realização & 5,02 & 4,96 & 5,06 & $\mathbf{1 0 , 0 0 5 * *}$ \\
Intuição & 4,87 & 4,81 & 4,93 & $2,068+$ \\
Liderança & 4,53 & 4,50 & 4,55 & \\
\hline
\end{tabular}

Nota: Significância: $\mathrm{p}<0,01=* *$, não significativa $=+$

Fonte: Elaboração própria com base em dados da pesquisa do PICJr 
Investigando-se a diferença entre as médias da auto-eficácia empreendedora e das atitudes relativamente aos grupos raciais, não foram encontradas significância quando os dados agrupam brancos e não brancos (pardo, negro, índigena e asiático). Ao se examinar as diferenças de médias com respeito a categorias de renda familiar - até $\mathrm{R} \$ 1000,00$, de $\mathrm{R} \$$ 1001,00 a 2500,00 e de 2501 em diante, a única diferença significativa $(\mathrm{p}<0,05)$ foi na atitude criatividade, mas não ficou clara qualquer tendência a desenvolver mais a criatividade de acordo com diminuição ou aumento de renda.

Quando a diferença entre as médias é examinada segundo a variável série do ensino médio (Tabela 3), os resultados apontam significância maior quanto à auto-eficácia empreendedora, em que se alcança o nível de significância de $\mathrm{p}<0,05$, indicando que à medida que os alunos progridem na educação e também se tornam mais velhos, há uma tendência para desenvolver mais a auto-eficácia empreendedora, talvez devido às oportunidades de fortalecer sobretudo as atitudes de controle pessoal e intuição (significativas no nível de $\mathrm{p}<0,01$ ). Mesmo assim, observa-se que as médias alcançadas, ainda distam muito do desenvolvimento pleno do potencial empreendedor dos alunos. As diferenças não se mostram significativas nas atitudes de criatividade, realização e liderança. Estes dados nos fazem questionar sobre o que está sendo feito e o que poderia ser feito no sentido de melhorar as chances de desenvolver mais a auto-eficácia empreendedora no geral e com respeito às atitudes.

Tabela 3. Comparação entre as médias da auto-eficácia empreendedora e das atitudes segundo a série do ensino médio.

\begin{tabular}{|c|c|c|c|c|c|}
\hline \multirow[b]{2}{*}{ Dimensão } & \multicolumn{4}{|c|}{ Série } & \multirow{2}{*}{$\begin{array}{c}\text { Teste de } \\
\text { Significânci }\end{array}$} \\
\hline & Total & $1^{\mathrm{a}}$ & $2^{\mathrm{a}}$ & $3^{a}$ & \\
\hline Auto-Eficácia Empreendedora & 4,82 & 4,78 & 4,81 & 4,86 & $3,221^{*}$ \\
\hline Criatividade & 4,44 & 4,43 & 4,41 & 4,47 & $968^{+}$ \\
\hline Controle Pessoal & 5,21 & 5,13 & 5,24 & 5,25 & $5,529^{* *}$ \\
\hline Realização & 5,02 & 4,98 & 5,04 & 5,03 & $1,329^{+}$ \\
\hline Intuição & 4,88 & 4,82 & 4,85 & 4,96 & $4,573^{* *}$ \\
\hline Liderança & 4,53 & 4,52 & 4,49 & 4,57 & $1,314^{+}$ \\
\hline
\end{tabular}

Nota: Significância: $\mathrm{p}<0,05=*, \mathrm{p}<0,01=* *$, não significativa $=^{+}$

Fonte: Própria autoria com base em dados da pesquisa do PICJr

Na Tabela 4 apresentam-se os valores da média geral no teste TAE, bem como nas cinco atitudes, segundo a experiência / exposição ao empreendedorismo e intenção de empreender. 
Tabela 4. Comparação entre as médias da auto-eficácia empreendedora e das atitudes a segundo experiência com empreendedorismo e a intenção de empreender.

\begin{tabular}{|c|c|c|c|c|c|c|}
\hline \multirow[b]{2}{*}{ Dimensão } & \multicolumn{5}{|c|}{ Experiência com Empreendedorismo e intenção de empreender } & \multirow[b]{2}{*}{$\begin{array}{c}\text { Teste de } \\
\text { Significância }\end{array}$} \\
\hline & Total & $\begin{array}{l}\text { Já teve um } \\
\text { negócio } \\
\text { próprio }\end{array}$ & $\begin{array}{c}\text { Já } \\
\text { participou } \\
\text { do negócio } \\
\text { de alguém }\end{array}$ & $\begin{array}{l}\text { Nunca teve } \\
\text { um negócio, } \\
\text { mas } \\
\text { gostaria de } \\
\text { ter }\end{array}$ & $\begin{array}{l}\text { Nunca teve } \\
\text { um negócio, } \\
\text { e não } \\
\text { gostaria de } \\
\text { ter }\end{array}$ & \\
\hline Auto-Eficácia Empreendedora & 4,82 & 4,88 & 4,83 & 4,82 & 4,60 & $9,008^{* * *}$ \\
\hline Criatividade & 4,44 & 4,53 & 4,49 & 4,42 & 4,26 & $\mathbf{5 , 6 5 4} 4^{* *}$ \\
\hline Controle Pessoal & 5,21 & 5,22 & 5,18 & 5,22 & 5,13 &, $855^{+}$ \\
\hline Realização & 5,02 & 5,10 & 5,08 & 5,02 & 4,63 & $14,174^{* * *}$ \\
\hline Intuição & 4,88 & 4,93 & 4,86 & 4,89 & 4,70 &, $3^{* *}$ \\
\hline Lideranca & 4,53 & 4,63 & 4,57 & 4,52 & 4,27 & $2,160^{+}$ \\
\hline
\end{tabular}

Nota: Significância: $\mathrm{p}<0,05=*, \mathrm{p}<0,01=* *, \mathrm{p}<0,001=* * *$, não significativa $=^{+}$

Fonte: Própria autoria com base nos dados da pesquisa dos alunos do PICJr

Na média geral se observa que a significância das diferenças entre as médias foi no nível de $\mathrm{p}<0,001$. Em realização a significância da diferença entre as médias também foi significativa no nível de $\mathrm{p}<0,001$. Em criatividade e intuição a significância foi no nível de $p$ $<0,01$. Os resultados em controle pessoal e liderança não atingiram significância, ainda que tendam a seguir um padrão de maiores para menores médias, à medida que varia a experiência/ envolvimento com um negócio - próprio ou de alguém - e a intenção de empreender ou não.

Prosseguiu-se analisando a influência da escolaridade dos pais na auto-eficácia empreendedora e nas atitudes que a compõem no TAE. Os resultados mostraram que apenas a atitude de controle pessoal foi significativa no nível de $p<0,05$. Porém, as médias mostram uma tendência de aumento com a maior escolaridade dos pais, mostrando diferenças um pouco maiores na auto-eficácia empreendedora, criatividade, controle pessoal. Nas atitudes intuição e liderança esta evolução foi muito discreta.

\section{Considerações Finais}

Os resultados demonstram que: mesmo sem qualquer exposição a atividades e iniciativas de educação empreendedora nas escolas, o potencial empreendedor dos alunos existe, sendo que a auto-eficácia empreendedora parece ser influenciada pelo ambiente familiar e social de que participam, especialmente quando os alunos tem oportunidade de serem expostos à experiência com seus próprios negócios, atividades de vendas; que este potencial é influenciado pela escolaridade dos pais; e que a influência do grupo racial não é homogênea e estimula diferentemente as atitudes que compõem este potencial empreendedor.

Ao longo do ensino, se demonstra por meio das diferentes séries ecolares de que participam os alunos, que há uma evolução discreta da auto-eficácia empreendedora; entretanto, parece que estes efeitos são bem menores do que os obtidos por influência de

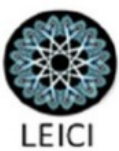


exposição às atividades típicas de empreendedores - envolvendo-se com vendas, com iniciar um negócio próprio ou participando/ajudando num negócio de outra pessoa.

Estes resultados parecem sugerir que, de fato, se houver a oferta de atividade/ iniciativas e cursos de empreendedorismo nas escolas, no ensino médio, ou até mesmo no ensino fundamental, a sociedade poderá se beneficiar muito do desenvolvimento do potencial empreendedor de seus jovens. Este tipo de experiência ajuda a fortalece-los e a criar alternativas para sua vida profissional.

Convém frisar que quão mais cedo a EE for oferecida, melhor, pois no ensino fundamental é que se tem melhores chances de formar o espírito e mentalidade empreendedoras; já, posteriormente, no nível superior, o objetivo da EE é outro: é o de desenvolver as habilidades empreendedoras (European Commission, 2012, p.44).

No estado de São Paulo já se estaria mais próximo desta possibilidade de inserção da educação empreendedora, visto que a Lei 1563 de 03 Março de 2015 já foi alterada pela Resolução SE 48 de 10/08/2016, e se criou o Plano Estadual de Educação Empreendedora, com o objetivo de incluir a EE como tema transversal às habilidades presentes no Currículo Oficial. Este plano tem como objetivo geral desenvolver competências empreendedoras que permitam que os alunos transformem ideias em soluções inovadoras, permitindo que tenham mais condições de decidir sobre seu futuro profissional e como gerar benefícios para si e para a sociedade. No ano de 2017, a meta 2 já tinha sido alcançada que foi a elaboração dos objetivos e da matriz de habilidade de EE. Ainda se teria muito a caminhar até ofertar de fato a EE para os alunos.

Mas, em termos de arcabouço legal, está mais próximo do que no plano federal em que o projeto de Lei no. 772 de 2015: poderá impactar na inserção da EE como transversal nível federal. Em dezembro de 2017 continuava em tramitação no Senado, com a relatoria.

Sugere-se que, em continuação deste estudo, se possam examinar as características psicométricas desta adaptação do TAE ao nosso idioma, estudando sua fidelidade, validade e testar a sua validade de critério. E assim, contribuir para sua melhoria, posteriormente, melhorando as afirmativas da escala de intuição.

\section{Agradecimentos}

Agradecemos aos alunos que auxiliaram em partes dessa pesquisa em momentos prévios, nominalmente: aos alunos do programa de iniciação científica ensino médio (Anderson Alves de Alencar, Karoline Aparecida Cia, Denise Knupp de Oliveira, Wevestton Lucas Conceição Sampaio e Jaqueline Massarelli Marsão); aos alunos de graduação que realizaram seus trabalhos de conclusão de curso sobre o tema (Iane Souza Silva, Paula Rosa Mendes de Souza, Leonardo Negrão Pereira, João Paulo de Faria Guarnieri e Liziane Ferreira Magalhães); e aos alunos do Programa Institucional de Bolsas de Iniciação Científica - PIBIC (Jéssica Cristina Izeppe e Diego Maradona Leite Nunes).

\section{Financiamento}

Financiamento: Este projeto de pesquisa teve financiamento do Fundo de Apoio ao Ensino, à Pesquisa e Extensão - FAEPEX (Processo: \# 169/13) e do Conselho Nacional de

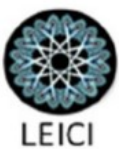


Desenvolvimento Científico e Tecnológico - CNPq (Bolsa de IC, Processo PRP Quota 2015), ambos da UNICAMP.

\section{Referências}

Ajzen, I. 1991. The Theory of Planned Behavior. Organizational and Human Decision Processes, 50, 179-211.

Athayde, R. \& HART, M. 2012. Developing a Methodology to Evaluate Enterprise Education Programmes. International Review of Entrepreneurship 10(3).

Confederation of British Industry - CBI. 2009. Emerging stronger: the value of education and skills in turbulent times. Education and Skills Survey. Oxford: Nord Anglia Education Ltd.

Bandura, A. 1997. Self-efficacy: The Exercise of Control. New York: Freeman.

Bandura, A. 1986. Social Foundations of Thought and Action: A Social Cognitive Theory. Englewood Cliffs N.J.: Prentice Hall.

Bandura A., \& Schunck, D., H. 1981. Cultivating competence, self-efficacy, and intrinsic interest through proximal self-motivation. Journal of Personality and Social Change, 41:586598.

Bird, B. 1988. Implementing Entrepreneurial Ideas: The Case for Intention. The Academy of Management Review, 13(3): 442-453.

Bruno, G. S. F., Choudhry, M. T., Marelli, E., \& Signorelli, M. 2016. The short- and long-run impacts of financial crises on youth unemployment in OECD countries. Applied Economics, 49:34, 3372-3394, DOI: 10.1080/00036846.2016.1259753. Disponível em: $<$ http://www.siecon.org/online/wp-content/uploads/2014/10/Bruno-Choudhry-MarelliSignorelli-148.pdf $>$.

Cooper, D; Schindler, P. S. (2003). Métodos de Pesquisa em Administração. São Paulo: Bookman, 2003. Capítulo 9: Escalas de Mensuração, p.196-215 e Capítulo 12: Instrumentos para comunicação com o respondente, p.272-297.

European Commission. 2012. Effects and impact of entrepreneurship programmes in higher education. Entrepreneurship Unit Directorate-General for Enterprise and Industry. B-1049 Brussels.

Greco, S. M. de S. S. 2017. (Coord.) Global Entrepreneurship Monitor Empreendedorismo no Brasil: 2016. Curitiba: IBQP.

Haynie, M. \& Shepherd, D. A. 2009. A Measure of Adaptive Cognition for Entrepreneurship Research. Entrepreneurship, Theory and Practice, May: 695-714.

Hmieleski, K. M., and Corbett, A. C. 2008. The contrasting interaction effects of improvisational behavior with entrepreneurial self-efficacy on new venture performance and entrepreneur work satisfaction. Journal of Business Venturing, 23(4):482-496.

Katz, J. A. \& Gartner, W. B. 1988. Properties of emerging organizations. Academy of Management Review, 13, 429-441.

Katz, J. A. \& Shepherd, D. A. 2003. Cognitive Approaches to Entrepreneurship Research, in Katz, J.A \& Lumpkin, T. (Eds.) Cognitive Approaches to Entrepreneurship Research (Advances in entrepreneurship Research, Firm Emergence and Growth) 6:1-10. Bingley UK:

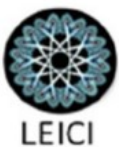


Emerald Group Publishing Limited.

Krueger, N. F. \& Carsrud, A. 1993. Entrepreneurship Intentions: Applying the Theory of Planned Behaviour. Entrepreneurship and Regional Development, 5: 315-330.

Global Employment Trends for Youth 2017: Paths to a better working future. 2017. International Labour Office - Geneva: ILO, 2017. ISBN 978-92-2-130109-7. Disponível em: $<$ http://www.ilo.org/wcmsp5/groups/public/---dgreports/---dcomm/--publ/documents/publication/wcms_598669.pdf>.

Lopes, R. M. A. 2013. Qual o perfil do empreendedor? Revista da ESPM, n. 2, 64-71.

Lopes, R. M. A., Lima, E. O., \& Nassif, V. M. J. 2017. Panorama sobre a educação para o empreendedorismo, in Ensino de Empreendedorismo no Brasil: panorama, tendências e melhores Práticas. Rose Mary Almeida Lopes (org.), pp. 21-54. Rio de Janeiro: Alta Books.

McCline, R.L., Bhat, S., \& Baj, P. (2000). Opportunity recognition: An exploratory investigation of a component of the entrepreneurial process in the context of the health care industry. Entrepreneurship Theory and Practice, 25:81-144.

Rauch, A. \& Frese, M. (2007). Let's put the person back into entrepreneurship research: A meta-analysis on the relationship between business owners' personality traits, business creation, and success. European Journal of Work and Organizational Psychology, 16:4, 353385.

Robinson, P.B., Stimpson, D.V., Huefner, J.C., \& Hunt, H.K. 1991. An attitude approach to the prediction of entrepreneurship. Entrepreneurship Theory and Practice, 15 (4):13-31.

Scherer, R., Adams, J., Carley, S. \& Wiebe, F. 1989. Role model performance effects on development of entrepreneurial career preference. Entrepreneurship Theory and Practice, 13(3), 53-81.

Shapero, A. 1981. Self-renewing economies. Economic Development Commentary, 5(Apr.), 19-22.

Shapero, A. 1982. Social dimensions of entrepreneurship, in C. Kent, D. Sexton \& K. Vesper (Eds.), The encyclopedia of entrepreneurship, pp. 72-90. Englewood Cliffs, NY: Prentice Hall.

Thompson, E. R. 2009. Individual Entrepreneurial Intent: Construct Clarification and Development of an Internationally Reliable Metric. Entrepreneurship Theory and Practice, May:669-694.

\section{Apêndice}

\begin{tabular}{|c|c|c|c|c|c|c|}
\hline Dimensão & \multicolumn{6}{|c|}{ Afirmativas (Atitudes) } \\
\hline Realização & $\begin{array}{l}\text { Não importa se } \\
\text { meu projeto de } \\
\text { vida não é bom. }\end{array}$ & $\begin{array}{l}\text { Eu trabalho duro } \\
\text { para que meus } \\
\text { projetos } \\
\text { escolares sejam } \\
\text { bem-sucedidos. }\end{array}$ & $\begin{array}{l}\text { É importante } \\
\text { terminar um } \\
\text { projeto, tão logo } \\
\text { quanto possível. }\end{array}$ & $\begin{array}{l}\text { Eu me sinto bem } \\
\text { quando um } \\
\text { projeto meu vai } \\
\text { bem. }\end{array}$ & $\begin{array}{l}\text { Eu tenho } \\
\text { orgulho do meu } \\
\text { projeto de vida } \\
\text { este ano. }\end{array}$ & $\begin{array}{l}\text { Vale a pena o } \\
\text { esforço de se } \\
\text { trabalhar duro } \\
\text { num projeto } \\
\text { escolar. }\end{array}$ \\
\hline Criatividade & $\begin{array}{l}\text { Eu não gosto de } \\
\text { professores que } \\
\text { sempre chegam } \\
\text { com novas } \\
\text { maneiras de } \\
\text { fazer as coisas. }\end{array}$ & $\begin{array}{l}\text { Acho que eu } \\
\text { mostro muita } \\
\text { imaginação no } \\
\text { meu curso. }\end{array}$ & $\begin{array}{l}\text { Acredito que } \\
\text { uma boa } \\
\text { imaginação } \\
\text { ajuda as pessoas } \\
\text { a fazerem as } \\
\text { coisas melhor. }\end{array}$ & $\begin{array}{l}\text { Gosto de aulas } \\
\text { em que o } \\
\text { professor utiliza } \\
\text { diferentes } \\
\text { formas de } \\
\text { ensino. }\end{array}$ & $\begin{array}{l}\text { Eu gosto de } \\
\text { lições que } \\
\text { realmente } \\
\text { forçam minha } \\
\text { imaginação. }\end{array}$ & $\begin{array}{l}\text { Eu não gosto de } \\
\text { aulas onde os } \\
\text { alunos precisam } \\
\text { contribuir com } \\
\text { novas ideias. }\end{array}$ \\
\hline
\end{tabular}




\begin{tabular}{|c|c|c|c|c|c|c|}
\hline Intuição & $\begin{array}{l}\text { Instinto me } \\
\text { ajuda a encontrar } \\
\text { soluções para os } \\
\text { problemas. }\end{array}$ & $\begin{array}{l}\text { Confio no meu } \\
\text { próprio instinto } \\
\text { na resolução de } \\
\text { problemas. }\end{array}$ & $\begin{array}{l}\text { Cometer erros é } \\
\text { uma boa maneira } \\
\text { de aprender. }\end{array}$ & $\begin{array}{l}\text { Se eu não souber } \\
\text { a resposta de um } \\
\text { problema, então } \\
\text { eu vou dar um } \\
\text { palpite/chute. }\end{array}$ & $\begin{array}{l}\text { Vou continuar } \\
\text { tentando } \\
\text { soluções } \\
\text { diferentes para } \\
\text { um problema, } \\
\text { em vez de } \\
\text { desistir. }\end{array}$ & $\begin{array}{l}\text { Se você não sabe } \\
\text { todos os fatos } \\
\text { sobre um } \\
\text { problema, então } \\
\text { não há forma de } \\
\text { você encontrar } \\
\text { uma resposta. }\end{array}$ \\
\hline Liderança & $\begin{array}{l}\text { Meus amigos } \\
\text { dizem que eu } \\
\text { sou um seguidor } \\
\text { e não um líder. }\end{array}$ & $\begin{array}{l}\text { Acredito que } \\
\text { posso convencer } \\
\text { as pessoas a } \\
\text { concordar } \\
\text { comigo. }\end{array}$ & $\begin{array}{l}\text { Eu sou bom em } \\
\text { motivar meus } \\
\text { colegas. }\end{array}$ & $\begin{array}{l}\text { Eu assumo a } \\
\text { responsabilida- } \\
\text { de de formar } \\
\text { grupos de estudo } \\
\text { na escola. }\end{array}$ & $\begin{array}{l}\text { Eu não gosto de } \\
\text { ser o centro das } \\
\text { atenções em sala } \\
\text { de aula. }\end{array}$ & $\begin{array}{l}\text { Eu sou bom em } \\
\text { fazer as pessoas } \\
\text { trabalharem bem } \\
\text { e juntas. }\end{array}$ \\
\hline Controle & $\begin{array}{l}\text { Acho que a } \\
\text { minha carreira } \\
\text { futura em grande } \\
\text { parte depende de } \\
\text { mim. }\end{array}$ & $\begin{array}{l}\text { Tenho uma boa } \\
\text { chance de } \\
\text { conseguir um } \\
\text { bom emprego no } \\
\text { futuro. }\end{array}$ & $\begin{array}{l}\text { Outras pessoas } \\
\text { irão obter } \\
\text { melhores } \\
\text { empregos do que } \\
\text { eu. }\end{array}$ & $\begin{array}{l}\text { É importante } \\
\text { planejar minha } \\
\text { carreira futura. }\end{array}$ & $\begin{array}{l}\text { Eu estou } \\
\text { preocupado que } \\
\text { não vou ter } \\
\text { sucesso em } \\
\text { minha vida } \\
\text { profissional } \\
\text { futura. }\end{array}$ & $\begin{array}{l}\text { Eu tenho muita } \\
\text { fé na minha } \\
\text { capacidade de } \\
\text { ser bem } \\
\text { sucedido na } \\
\text { minha carreira } \\
\text { futura. }\end{array}$ \\
\hline
\end{tabular}

Figura 4. Itens do Teste de Atitudes Empreendedoras - ATE

Fonte: recuperado e adaptado de Athayde \& Hart (2012).

\section{Lista das escolas de Limeira que participaram da pesquisa}

"EE Brasil”, "EE Castello Branco”, “EE Dom Idílio José Soares”, “EE Irmã Maria de Santo Inocêncio Lima", "EE Prof. Antônio Perches Lordello", "EE Prof. Antônio de Queiroz", "EE Prof. Arlindo Silvestre", "EE Prof. Ary Leite Pereira", "EE Prof. Ataliba Pires do Amaral", "EE Prof. Dorivaldo Damm", "EE Prof. Ely de Almeida Campos", "EE Prof. Gabriel Pozzi", "EE Prof. Gustavo Peccinni", "EE Prof. Lázaro Duarte do Pateo", "EE Prof. Paulo Chaves", "EE Prof. William Silva", "EE Profa. Carolina Arruda Vasconcelos", "EE Profa. Leontina Silva Bush", "EE Profa. Margarida Paroli Soares", e "EE Profa. Ruth Ramos Cappi”. 